\title{
The Effect of $\alpha_{2}$-Phase $\left(\mathrm{Ti}_{3} \mathrm{Al}\right)$ on the Wear Behavior of Titanium Alloys Added Small Amounts of Fe
}

\author{
I. SiMSEK* AND D. OZYUREK \\ Karabuk University, Technology Faculty, Manufacturing Eng., 78100 Karabuk, Turkey
}

\begin{abstract}
In the present study, the effect of $\alpha_{2}$-phase $\left(\mathrm{Ti}_{3} \mathrm{Al}\right)$ on the wear behavior of the titanium alloys is investigated by adding different amounts of (0.3-0.5\%) Fe to the Ti8Al2.5Sn and Ti5Al2.5Sn alloys, which are produced by the mechanical alloying. The pre-formed green compacts were sintered at $1200^{\circ} \mathrm{C}$ for one hour. The sintered samples were characterized by scanning electron microscope, X-ray diffraction, and the hardness and density measurements. The wear tests were performed under $30 \mathrm{~N}$ load, at four different sliding distances $(400-1600 \mathrm{~m})$ and with a constant speed of $1 \mathrm{~ms}^{-1}$. As a result of the study, it was understood that the $\alpha_{2}$-phase $\left(\mathrm{Ti}_{3} \mathrm{Al}\right)$ in the structure occurred at the grain boundary during the sintering process. With an increase in Fe addition to the Ti8 $\mathrm{Al} 2.5 \mathrm{Sn}$ and Ti5 Al2.5Sn alloys, the density and hardness of the alloy increased as well. As a result of the wear tests, it was determined that the least weight loss occurred in Ti5Al2.5Sn alloy with a $0.5 \%$ Fe addition.
\end{abstract}

DOI: 10.12693/APhysPolA.131.99

PACS/topics: $81.40 . \mathrm{Pq}$

\section{Introduction}

Due to its low density, good mechanical properties and corrosion resistance, industrial use of titanium alloys is increasing every day [1]. These alloys are classified in four groups as $\alpha$-alloys, near $\alpha$-alloys, $\alpha-\beta$ alloys and $\beta$ alloys according to their microstructure. Titanium is a polymorphic crystalline element having hexagonal close packed (hcp) structure in low temperatures and bodycentered cubic (bcc) structure above $882.5^{\circ} \mathrm{C}[2-6]$. However, its alloys have low wear resistance and hardness. These are alloys containing $\alpha$-stabilizer elements such as $\alpha$-alloys, aluminum and tin in their composition $[5,6]$. One of the most important commercially available $\alpha$ titanium alloys is Ti5Al2.5Sn alloy. Ti5 Al2.5Sn alloy is used in production of turbine blades in jet engines due to its advantages such as good weldability, stability in high temperatures and oxidation resistance. Strength increase in titanium alloys produced with aluminum and tin addition is provided by solid solution strengthening mechanism. Addition of these elements also changes the allotropic transformation temperature. As aluminum is $\alpha$-phase constitutive element, it makes $\alpha$-phase stable significantly. It increases the strength of the alloy and also decreases its density $[6,7]$. When the amount of aluminum added into the alloy is increased, $\alpha_{2}$ phase $\left(\mathrm{Ti}_{3} \mathrm{Al}\right)$ formed within the structure causes brittleness [8]. Furthermore, as the amount of iron added into titanium alloys increases, $\beta$ phase is formed around grain boundaries, which is in small and increasing amounts. $\beta$ phase, concentrated at grain boundaries, prevents grain growth during recrystallization $[7,9]$. Although titanium alloys show superior mechanical and physical properties, these are insufficient in applications with which moving contact

*corresponding author; e-mail: ijlalispir@karabuk.edu.tr is due to low wear resistance. During the operation of these alloys with friction, oxide layer providing corrosion resistance is deteriorated, thereby material loss increases along with wear effect [10]. In this study, $\alpha_{2}$ phase precipitation during sintering procedure was aimed in titanium alloys produced by adding $\mathrm{Fe}$ in different amounts (0.3-0.5 wt\%) into Ti8Al2.5Sn and Ti5Al2.5Sn titanium alloys produced with mechanical alloying method. Also, the effect of the precipitated $\alpha_{2}$ phase on wear behaviors of the alloys is examined.

\section{Materials and method}

In this study, wear behaviors of $\mathrm{Ti}_{3} \mathrm{Al}$ alloy of $\alpha_{2}$ phase are examined which is formed in the microstructure by adding $\mathrm{Fe}$ in different amounts (0.3-0.5 wt\%) into Ti8Al2.5Sn and Ti5Al2.5Sn titanium alloys produced with mechanical alloying method. In experimental studies, aluminum $(\mathrm{Al})$, tin $(\mathrm{Sn})$ and iron $(\mathrm{Fe})$ powders were used along with titanium with $99.7 \%$ purity and -100 mesh particle dimension. Elemental powders for production of titanium alloys were prepared with a $1 / 10000 \mathrm{~g}$ precision scale. The compositions prepared were alloyed in 8000 series SPEX mechanical alloying device. Mechanical alloyed powders were cold pressed under $620 \mathrm{MPa}$ pressure for wear and characterization studies and green compacts of $10 \times 7 \mathrm{~mm}^{2}$ size were produced. After cold pressing, green compacts were sintered in argon atmosphere. After keeping the samples at $880^{\circ} \mathrm{C}$ temperature $\left(10^{\circ} \mathrm{C} / \mathrm{min}\right)$ for $30 \mathrm{~min}$, they were held at $1150^{\circ} \mathrm{C}$ for $5 \mathrm{~min}$ and sintered at $120{ }^{\circ} \mathrm{C}$ for $60 \mathrm{~min}$ before cooling to room temperature in furnace. After preparation of all samples for microstructure examinations according to metallographic procedures, they were etched using $5 \mathrm{ml} \mathrm{H} \mathrm{O}_{2}-10 \mathrm{ml} 40 \% \mathrm{KOH}-20 \mathrm{ml} \mathrm{H} \mathrm{H}_{2} \mathrm{O}$ etchant for $60 \mathrm{~s}$. The alloys produced were characterized with scanning electron microscope (SEM), X-ray diffraction (XRD) and hardness and density measurements. Wear tests were carried out in pin-on-disc type wear device according to the ASTM-G99-05 standard. In wear tests, 
$1 \mathrm{~ms}^{-1}$ sliding rate, $30 \mathrm{~N}$ load and four different (400$1600 \mathrm{~m}$ ) sliding distances were used. In wear tests, abrasive disc and sample surfaces were cleaned with acetone prior to each test. Worn samples were weighed in precision balance and weight losses were determined. AISI 4140 steel disc with $230 \mathrm{~mm}$ diameter, $20 \mathrm{~mm}$ thickness and 60-64 HRC hardness were used as counter material in wear tests. The worn sample surfaces were examined with SEM after completion of the wear tests.

\section{Results and discussion}

Figure 1 gives the SEM images of titanium alloys produced by Ti8Al2.5Sn (0.3-0.5 wt\%) Fe and Ti5Al2.5Sn (0.3-0.5 wt\%) Fe addition. In the SEM images, it was observed that the alloys formed $\alpha_{2}$ phase (white phases) during sintering procedure and these phases were distributed homogeneously. It was understood that $\mathrm{Ti}_{3} \mathrm{Al}$ intermetallic phase (Fig. 1a) were surrounded by the matrix and it had small (sub- $\mu \mathrm{m})$ dimension. Figure 1a and $\mathrm{b}$ shows that $\alpha_{2}$ phase in the structure is greater and SEM graphs in Fig. 1c and d show that the intermetallic phase in the microstructure is smaller.

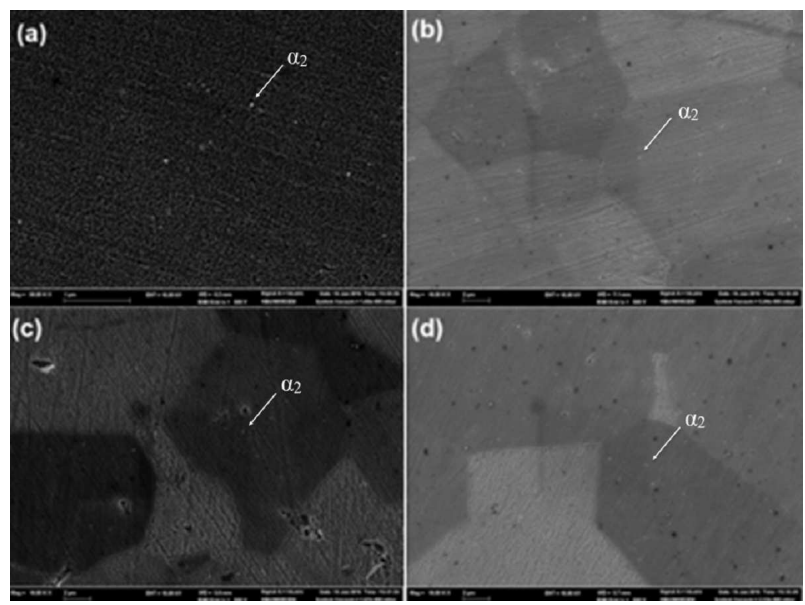

Fig. 1. SEM images of the titanium alloys produced: (a) Ti8Al2.5Sn-0.3Fe, (b) Ti8Al2.5Sn-0.5Fe, (c) Ti5Al2.5Sn-0.3Fe, and (d) Ti5Al2.5Sn-0.5Fe.

In Figure 2, XRD results of Ti8Al2.5Sn-0.5Fe alloy are given. As understood from XRD results, $\alpha_{2}$ phase $\left(\mathrm{Ti}_{3} \mathrm{Al}\right)$ that was aimed to be formed in the structure at the end of sintering procedures was produced. It is known that different inter-metal compounds $\left(\alpha_{2}-\mathrm{Ti}_{3} \mathrm{Al}\right.$ and $\gamma$-TiAl) were formed depending on amounts of $\mathrm{Al}$ and $\mathrm{Ti}$ elements in $\mathrm{Al}-\mathrm{Ti}$ phase diagram and alloying conditions. In this study, it was determined that $\mathrm{Ti}_{3} \mathrm{Al}$ and $\mathrm{TiAl}$ reinforcement phases, which were expected to form in the structure with X-ray diffraction, were formed with in situ reactions. This in situ reaction takes place as

$$
3 \mathrm{Ti}+\mathrm{Al} \rightarrow \mathrm{Ti}_{3} \mathrm{Al} .
$$

In situ titanium aluminate intermetallic compounds, formed in the structure, are intermetallic compounds having a crystal structure different from metals.

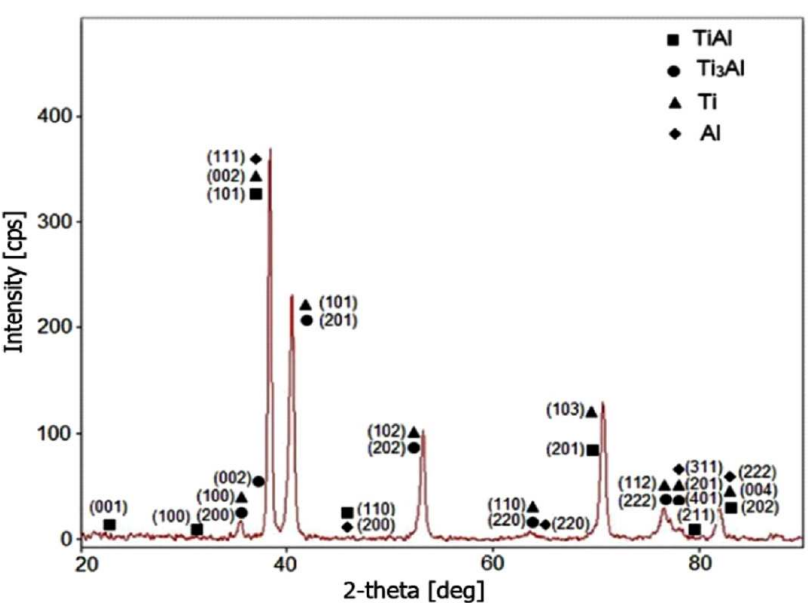

Fig. 2. XRD results of Ti8Al2.5Sn-0.5Fe alloy.

Figure 3 gives the hardness and density variation of titanium alloys produced with mechanical alloying. Figure $3 \mathrm{~b}$ indicates that the lowest density value is obtained for the alloy with Ti5Al2.5Sn-0.3Fe composition, although it was expected to be obtained in the alloy with Ti8Al2.5Sn-0.3Fe. This result is attributed to the pores developed during the cold pressing and sintering procedure. From the hardness variation given in Fig. 3a, it can be seen that the highest density is obtained in the alloy with Ti8Al2.5Sn-0.3Fe composition. Accordingly, hardness and density measurement values of Ti8Al2.5Sn alloys support each other. Aluminum (8 wt\%) making $\alpha$ phase in the titanium alloy stable increases solid solution strengthening. Moreover, hardness is further increased with the effect of $\alpha_{2}$ phase precipitations with $0.3 \% \mathrm{Fe}$ addition. $\alpha_{2}$ phase $\left(\mathrm{Ti}_{3} \mathrm{Al}\right)$ can be formed around grain boundaries in $\mathrm{Ti}-\mathrm{Al}$ alloys [11].

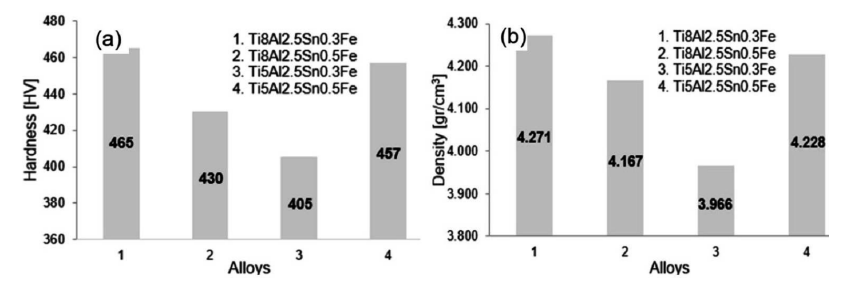

Fig. 3. Hardness (a) and density (b) changes of titanium alloys produced with mechanical alloying.

Figure 4 shows the weight losses (a) and wear rates (b) of titanium alloys produced with mechanical alloying under $30 \mathrm{~N}$ of load, $1600 \mathrm{~m}$ of sliding distance and $1 \mathrm{~ms}^{-1}$ of constant sliding speed. Depending on the increase in sliding distance, weight losses increase in all samples. On comparison of hardness results given in Fig. $3 \mathrm{~b}$ and weight losses obtained at the end of wear tests, the results seem to support each other. The lowest weight loss was seen to be obtained in the alloy with Ti8Al2.5Sn$0.3 \mathrm{Fe}$ addition having the highest hardness (465 HV). The highest weight loss was seen to be obtained in the 
alloy with Ti5Al2.5Sn-0.3 Fe addition having the lowest hardness (405 HV). In samples with Ti8Al2.5Sn-0.3 Fe addition, $\alpha_{2}$ phase $\left(\mathrm{Ti}_{3} \mathrm{Al}\right)$, formed homogeneously at the grain boundaries, affects hardness and wear resistance. Figure 5 gives the worn surface SEM images of titanium alloys produced with mechanical alloying.
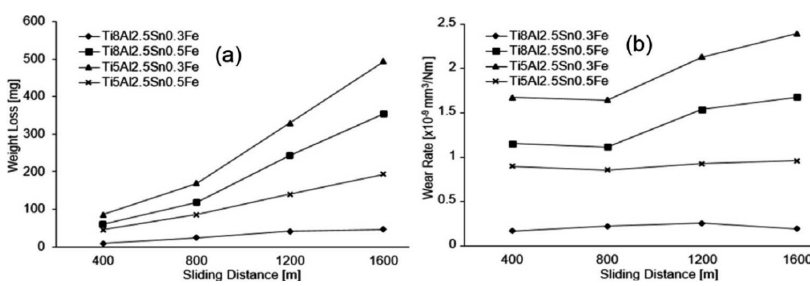

Fig. 4. Weight losses (a) and wear rates (b) depending on sliding distance.

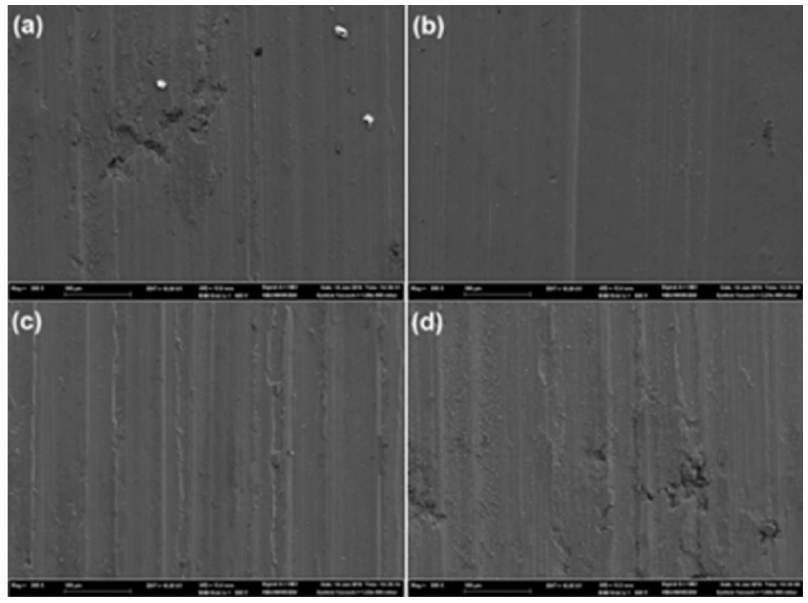

Fig. 5. Worn surface SEM images of the titanium alloys: (a) Ti8Al2.5Sn-0.3Fe, (b) Ti8Al2.5Sn-0.5Fe, (c) Ti5Al2.5Sn-0.3Fe, and (d) Ti5Al2.5Sn-0.5Fe.

Figure 5 shows that the plastic deformation is smaller in $\mathrm{Ti} 8 \mathrm{Al} 2.5 \mathrm{Sn}(0.3-0.5)$ (Fig. 5a and b) which has high amount of aluminum while there is more plastic deformation in Ti5Al2.5(0.3-0.5) (Fig. 5c and d) which has low amount of aluminum. It is thought that much amount of $\alpha_{2}$ phases in Fig. 1a and $\mathrm{b}$ is the cause of this result. On examination of the Ti5Al2.5Sn-0.3Fe alloy worn surface in which the highest weight loss and wear rate were obtained (Fig. 5c), it is understood that heavy plastic deformation and abrasion take place on sample surface. Moreover, another point observed on worn surfaces were obvious grooves formation. According to the hardness results, Fig. 3a, as aluminum amount added into the titanium increased, hardness increases as well.

\section{Conclusion}

The results obtained from the present experimental study are given below.
- With $0.3 \%$ and $0.5 \%$ Fe addition into Ti8Al2.5Sn and Ti5Al2.5Sn ( $\alpha$ alloy) alloys produced with mechanical grinding method, $\alpha_{2}$ phase precipitations are seen in all alloys.

- In these alloys, density ratios are increased with Fe addition by $0.3 \%$ and $0.5 \%$. However, density values are found lower than theoretical density calculations.

- Weight loss results of the alloys produced support the hardness test results. The lowest weight loss was obtained with Ti8Al2.5Sn-0.3 Fe addition having the highest hardness value $(465 \mathrm{HV})$ while the highest weight loss was obtained with Ti5Al2.5Sn$0.3 \mathrm{Fe}$ addition having the lowest hardness value (405 HV).

\section{Acknowledgments}

The authors are pleased to acknowledge the financial support for this study from Karabuk University Scientific Research Projects Department (KBÜ-BAP-15/2 -DR-026).

\section{References}

[1] C. Chunxiang, H. BaoMin, Z. Lichen, L. Shuangjin, Mater. Des. 32, 1684 (2011).

[2] R. Wanhill, S. Barter, Springer Briefs Appl. Sci. Technol. 2, 5 (2012).

[3] C. Veiga, J.P. Davim, A.J.R. Loureiro, Rev. Adv. Mater. Sci. 32, 133 (2012).

[4] P. Muneshwar, S.K. Singh, B. Pant, S.C. Sharma, M.C. Mittal, Trans. Indian Inst. Met. 61, 77 (2008).

[5] C. Leyen, M. Peters, Titanium and Alloys, Fundamentals and Applications, Wiley-VCH, Köln 2003, p. 11.

[6] ASM Metals Handbook, Properties and Selections: Nonferrous Alloys and Special-Purpose Materials, Vol. 2, ASM International, USA 1991, p. 1618.

[7] G. Lütjering, J.C. Williams, Titanium, 2nd ed., Springer, Heidelberg 2007, p. 337.

[8] R.I. Jaffee, N.E. Promiesel, The Science, Technology, and Applications of Titanium, 1st ed., Pergamon Press, Oxford 1970, p. 851.

[9] C. Massaro, P. Rotolo, F. De Riccardis, E. Milella, A. Napoli, M. Wieland, M. Textor, N.D. Spencer, D.M. Brunette, J. Mater. Sci. Mater. Med. 13, 535 (2002).

[10] D.M. Brunette, B. Tengwall, M. Textor, P. Thomsen, Titanium in Medicine, Springer Verlag, Heidelberg 2001, p. 485.

[11] D. Özyürek, S. Tekeli, High Temp. Mater. Process. 30, 175 (2011). 